\title{
BMJ Open Is the perceived impact of disciplinary procedures on medical doctors' professional practice associated with working in an open culture and feeling supported? A questionnaire among medical doctors in the Netherlands who have been disciplined
}

\author{
Berber S Laarman (D) , ${ }^{1}$ Renée J R Bouwman, ${ }^{2}$ Anke J E de Veer, ${ }^{2}$ Roland D Friele ${ }^{3}$
}

To cite: Laarman BS, Bouwman RJR, de Veer AJE, et al. Is the perceived impact of disciplinary procedures on medical doctors' professional practice associated with working in an open culture and feeling supported? A questionnaire among medical doctors in the Netherlands who have been disciplined. BMJ Open 2020;10:e036922. doi:10.1136/ bmjopen-2020-036922

- Prepublication history for this paper is available online. To view these files, please visit the journal online (http://dx.doi. org/10.1136/bmjopen-2020036922).

Received 13 January 2020 Revised 25 August 2020 Accepted 23 September 2020

Check for updates

(C) Author(s) (or their employer(s)) 2020. Re-use permitted under CC BY-NC. No commercial re-use. See rights and permissions. Published by BMJ.

For numbered affiliations see end of article.

Correspondence to

Berber S Laarman;

b.s.laarman@vu.nl

\begin{abstract}
Introduction Disciplinary procedures can have a negative impact on the professional functioning of medical doctors. In this questionnaire study, doctors' experience with open culture and support during a disciplinary procedure is studied to determine whether open culture and support are associated with perceived changes in the professional practice of doctors.
\end{abstract}

Methods All doctors who received a warning or a reprimand from the Dutch Medical Disciplinary Board between July 2012 and August 2016 were invited to fill in a 60-item questionnaire concerning open culture, perceived support during the disciplinary procedure and the impact of the procedure on professional functioning as reported by doctors themselves. The response rate was $43 \%(n=294)$.

Results A majority of doctors perceive their work environment as a safe environment in which to talk about and report incidents (71.2\% agreed). Respondents felt supported by a lawyer or legal representative and colleagues ( $92.8 \%$ and $89.2 \%$, respectively). The disciplinary procedure had effects on professional practice. Legal support and support from a professional confidant and a professional association were associated with fewer perceived changes to professional practice.

Conclusion Our study shows that doctors who had been disciplined perceive their working environment as open. Doctors felt supported by lawyers and/or legal representatives and colleagues. Legal support was associated with less of a perceived impact on doctors' professional practice.

\section{INTRODUCTION}

Legal procedures in healthcare, such as disciplinary, complaint or claim procedures, can have negative consequences for the health and professional functioning of the healthcare professional. ${ }^{1-4}$ Disciplinary procedures following adverse medical events can be
Strengths and limitations of this study

This study offers valuable insights into the perceived impact of disciplinary procedures, a relevant topic given efforts to improve healthcare quality, as similar complaint procedures exist across jurisdictions.

- The response rate was moderate, which may have caused a non-response bias.

- The study population was not comparable with the Dutch population of doctors in terms of age and gender.

- This study has a retrospective design, and the impact is based on self-reported experiences.

particularly harmful as adverse medical events are often traumatic experiences in their own right. Some doctors can even become a 'second victim' because of the event, meaning 'a healthcare provider involved in an unanticipated adverse patient event (...) become(s) victimised in the sense that the provider is traumatised by the event'. ${ }^{5-8}$

The additional impact of harmful legal proceedings raises concerns about 'defensive medicine'. ${ }^{9}$ As a concept, defensive medicine originated in the USA. Over the years, several substantially similar and overlapping definitions of defensive medicine have been offered, holding that defensive medicine includes all medical actions that physicians do without considering them the standard of care according to their clinical knowledge; these actions are meant to shield physicians from negligence or malpractice lawsuits filed by patients or their families'. ${ }^{10}$

European authors have adopted the concept and have recently begun to adapt 
Box 1 Information about the Dutch disciplinary system

The Dutch disciplinary system as set down in the Individual Healthcare Professions Act (BIG Act) is aimed at correcting professionals' behaviour, improving healthcare quality, and learning. Patients and other parties with a direct interest (the Dutch Healthcare Inspectorate, employers, or, under certain conditions, colleagues) can file a complaint with a regional Medical Disciplinary Board. There is one possibility for appeal, with the Central Disciplinary Board. Although the procedure places the professional conduct of individual doctors under scrutiny, the disciplinary procedures do not have the formal purpose of punishing doctors. A valid complaint does not entitle patients to financial compensation. Patients seeking financial compensation can file a claim with the healthcare institution, which is then often settled between parties before it is handled in court. The BIG Act sets out two disciplinary standards. The first refers to individual healthcare; the standard is not met if a patient's need for care is neglected, for example, if the patient is given incorrect information, if there is an incorrect or delayed diagnosis or if there is a failure to perform a treatment. The second disciplinary norm refers to the general interest embodied in proper pursuit of the profession. This includes administrative actions, dealing with colleagues or actions in the media. The conduct of healthcare professionals assessed under disciplinary standard (1) is measured against the professional standard. The professional standard is composed of the state of the art of medical practice, which the disciplinary boards determine based inter alia on relevant guidelines, protocols, scientific publications and case law. ${ }^{51} 52$ If a complaint is judged valid, doctors can be disciplined with (in increasing order of the gravity of the measure) a warning, a reprimand, a monetary fine, a conditional or definite suspension, withdrawal of the right to perform certain treatments or the right to re-register (in cases where a professional voluntarily resigns from a register) or removal from the register. Professionals receive a warning when their behaviour was not entirely correct, yet not reprehensible. Professionals who acted in breach of the professional standard but who are still fit for unconditional practice receive a reprimand. In practice, the line between a warning and a reprimand can be vague. Although other countries, such as Germany, the UK and the USA, have disciplinary systems where comparable measures can be imposed, there are also important differences. For instance, there are differences in definitions used (such as fitness to practice vs professional misconduct), and the structures and levels of the bodies handling them, and the likelihood of a formal judgement after a complaint has been received can vary greatly. ${ }^{53}{ }^{54}$ These differences in procedural characteristics have to be taken into account when comparing research outcomes.

it to apply to their respective legal cultures, which are often not as susceptible to medical liability claims as those in the USA. ${ }^{1011}$ Fear of loss of reputation, triggered by shame, and a social culture oriented to individual blame are identified as complementary triggers of defensive medicine. ${ }^{10}$ A recent study by Assing Hvidt et $a l^{12}$ into Danish general practitioners' (GP) understanding of defensive medicine identified fear of external demands such as patient pressure, system pressure, the pressure to conform to evidence-based guidelines, peer pressure or even self-pressure, resulting from fear of harming the patient, as potential factors of defensive medicine. Assing Hvidt et $a l^{12}$ consequently defined defensive medicine as 'unnecessary and meaningless actions driven by external demands instead of a focus on the patient's problem'.

Defensive medicine can be detrimental to the quality of healthcare and lead to unnecessarily high costs. ${ }^{13}$ But it can also be argued that defensive medicine has positive effects as well. Therefore, Summerton distinguishes between positive and negative factors of defensive medicine. ${ }^{14}$ Negative practices occur when doctors do not perform at a socially and clinically ideal level. Negative practices include 'increased referral rate' and 'increased diagnostic testing'. Positive practices are 'more detailed note-taking' and 'more detailed explanation of procedures to patients' and are considered quality improvements.

Quality improvement has been a priority in healthcare, and being open and learning from mistakes has been a particular focus. ${ }^{15-17}$ But being open can be difficult. Professionals' own emotional distress, shame, lack of communication skills and fear of patient's reaction can be barriers to openness. Fears associated with the prevalence of blame culture, such as the risk of legal or reputational consequences and the lack of support from peers and the institution, further decrease professionals' willingness to disclose adverse events. ${ }^{18} 19.20$

A lack of proactive disclosure and a perceived lack of willingness to learn, however, are the most pressing reasons for patients to file a complaint (whether disciplinary or otherwise) or a claim. ${ }^{21} 22$ To break this vicious cycle and facilitate disclosure, efforts are being made to move from a blame culture to a 'just culture' in healthcare. In a just culture, it is safe to disclose incidents, which are investigated respectfully and without stigmatising or punishing professionals. Furthermore, in a just culture, professionals are supported after adverse medical events. ${ }^{23-25}$ Therefore, openness and supporting professionals are elements of a just culture that aid learning and quality improvement.

In the context of these developments, disciplinary procedures have been the subject of increasing criticism in the Netherlands. Critics raise questions about the impact of disciplinary procedures and whether or not this leads to higher quality of care. ${ }^{26-28}$ Especially controversial was the (recently abolished) disclosure of disciplinary measures online and in regional newspapers. To study the impact of publishing disciplinary measures on doctors' health and professional functioning, we conducted a survey study in 2016. Responding doctors mentioned several changes to professional practice, such as avoiding patients similar to the complainant. ${ }^{1}$ Doctors whose disciplinary measures were disclosed reported a greater impact. We concluded that although some of the reported changes in professional practice might have a positive outcome, most are associated with defensive medicine. These findings suggest disciplinary procedures can obstruct the primary aim of disciplinary law: improving the quality of professional practice (see box 1). 
Taking the extensive body of literature concerning second victims into account, ${ }^{5-7} 2930$ we concluded that 'supporting doctors after complaints and patient safety incidents, enabling them to learn from mistakes and aiding them in disclosure, should be systematically embedded to ensure doctors' and patients' best interests'. Plews-Ogan $e t a l^{31}$ use the term 'post-traumatic growth' as described by Tedeschi and Calhoun ${ }^{32}$ to demonstrate how supporting healthcare professionals after adverse medical events can even help doctors to become better doctors. Peer support, talking to the patient, becoming an expert about the cause of the event and learning from the event are all coping mechanisms that promote growth. Therefore, we hypothesised that supporting doctors might reduce the negative impact of disciplinary procedures and might result in learning instead.

However, disciplinary procedures occur outside the work environment, and complaints are individual and confidential, which means that supervisors and/or colleagues are not informed about the procedure unless the professional takes the initiative to inform them himself or herself. The stigmatic nature of disciplinary complaints possibly hinders doctors from seeking or receiving support. Second, a disciplinary complaint is not necessarily related to the occurrence of an adverse medical event. Therefore, we do not know whether support within the institution extends to support during disciplinary procedures and whether this support is enough to mitigate the negative impact of disciplinary procedures on professional functioning.

Gaining insight into these issues is important as disciplinary procedures are meant to contribute to quality improvement by correcting professionals' behaviour. Nurturing a culture that is open and supports doctors after adverse medical events potentially aids doctors' recovery and possibly helps the doctor learn from the event. The hypothesis is that supporting doctors may mitigate the negative impact of the procedure. As a disciplinary procedure is supposed to be a learning experience, this study investigates the extent to which doctors in the Netherlands experience their working environment as a safe environment where they can be open about incidents and whether an open culture and perceived support during the disciplinary procedure are associated with the perceived occurrence of changes to professional practice resulting from the disciplinary procedure.

\section{Aim and research questions}

This study is part of a larger project conducted in 2016 to gain insight into the experiences of Individual Healthcare Professions Act (BIG)-registered healthcare professionals with impact from a disciplinary procedure, a disciplinary measure and the publishing of a disciplinary measure. In the original study, we differentiated between healthcare professionals getting a warning and a reprimand (see box 1 for the difference between disciplinary measures). At the time, reprimands were publicly disclosed, but warnings were not. Since April 2019, reprimands are only disclosed when the disciplinary judge considers disclosure necessary. Therefore, the distinction between warnings and reprimands was not maintained in this study's analyses.

In our questionnaire, we included questions related to open culture and perceived support during disciplinary procedures. This study aims to gain insight into the relationship between the experienced open culture and support on the one hand and changes in professional practice after a disciplinary measure on the other hand. The research questions were the following:

1. To what extent do Dutch medical doctors who received a disciplinary measure perceive their work environment as an open culture?

2. To what extent do Dutch medical doctors who received a disciplinary measure experience support during the disciplinary procedure?

3. To what extent do Dutch medical doctors report changes in their professional practice after a disciplinary measure?

4. Is there a relationship between an open culture and support, and perceived changes in professional practice after a disciplinary measure?

\section{METHODS}

\section{Study population and data collection}

This study focused on all Dutch medical doctors who received a warning or reprimand from the Disciplinary Board during the period July 2012 to August 2016. To create a homogeneous study population with comparable contextual factors such as education, all healthcare professionals other than medical doctors were removed from the data set. Doctors were enrolled in the study through disciplinary boards. All doctors with a reprimand or warning received a letter in September 2016 inviting them to fill in a questionnaire online. Two reminder letters were sent to increase the response rate. Privacy was considered very important given the sensitivity of the subject, so in close consultation with the disciplinary boards and the Ministry of Health we took the following measures:

- All letters were sent by the disciplinary board; the doctors remained anonymous for the researchers.

- A privacy policy was drawn up describing the process. This privacy policy was sent with the letter requesting participation in the study.

- All letters were sent in a plain white envelope without sender address, and the word 'confidential' was printed on the envelope.

- For privacy reasons, no response records were kept, so the two reminder letters were sent to all professionals.

- The disciplinary boards received no information about which doctors did or did not respond, and neither did the researchers. 


\section{Questionnaire}

We used a prestructured questionnaire, which means that respondents only needed to answer questions relevant to them. For example, if question 3 'Is this your current profession?' was answered 'no', the respondents did not have to answer questions about their work environment. The prestructured questionnaire was developed by the research group. The questionnaire is based on insights from the national and international literature concerning the impact of disciplinary procedures and on questionnaires used in other studies. ${ }^{23334}$ We used existing questionnaires on the impact of disciplinary procedures as a basis for this study. Those questionnaires were combined and adjusted. Besides general characteristics (respondent's characteristics and occupation), the questions relevant for this study concerned the open culture, support and changes to professional practice.

Open culture:

- Open culture as a concept was not introduced separately. Agreement with three statements about a perceived open culture in the direct work environment was measured using a 5-point scale ranging from 'totally agree' (1) to 'totally disagree' (5). The statements were adapted from Heuver et al. ${ }^{35}$

Support:

- Six questions about the extent of perceived support during the procedure from people in the work environment (colleagues, supervisor, lawyer or other legal representative, complaints officer, (professional) confidant, professional association) were measured on a 5-point scale: 'a lot of support' (5), 'a little support' (4), 'no support, but no obstruction either' (3), 'a little obstruction' (2) and 'a lot of obstruction' (1).

Changes to professional practice:

- One question about the perceived influence of the disciplinary procedure on professional practice with four answer categories was measured: the procedure had no influence, the procedure had a mostly positive influence, the procedure had both a positive and a negative influence and the procedure had a mostly negative influence.

- Eleven statements about changes in their professional practice due to the disciplinary procedure, based on a review of the literature, ${ }^{2-4}$ were measured.

To check the face validity of the questionnaire, we asked the members of advisory committees of medical professionals, disciplinary board members, the Patient Federation of the Netherlands and the Ministry of Health, Welfare and Sports to review the questionnaire and give their comments (in writing). The questionnaire was adjusted based on their suggestions and then sent to 10 healthcare professionals. As the original study involved BIG-registered healthcare professionals in general, not just medical doctors, the questionnaire was sent to four healthcare psychologists, four medical doctors, one nurse and one physiotherapist registered under the BIG Act. After answering the draft questionnaire, each professional was asked (in writing) whether the questions were properly understandable and clearly formulated, whether the answer categories were correct, whether they thought any answer categories or questions were missing, whether it was easy to fill in and whether the questionnaire was logically structured. This method can be considered a form of retrospective cognitive interviewing, ${ }^{36}$ and the feedback was used to draw up the final version of the questionnaire.

\section{Study population}

The response rate was $43 \% \quad(n=294)$. The questionnaires of the following classes of respondents, which may overlap, were removed from the data file: respondents who (1) indicated that they had not received a reprimand or warning $(\mathrm{n}=37)$, (2) stated that the disciplinary process had not yet been completed $(n=5)$, (3) filled in less than half of the questions $(n=2)$ and (4) had an occupation other than medical doctor, for example, a nurse $(n=84)$. A total of 210 respondents remained in the data file.

\section{Statistical analyses}

Descriptive analyses were performed on the measured variables.

A scale $(\alpha=0.86)$ was constructed from the three items concerning open culture in the work environment. The support items did not fit into one scale. One scale was constructed from 10 of the 11 items measuring changes in professional practice $(\alpha=0.82)$. One item did not fit into this scale. New variables on open culture and changes in professional practice were created for the scales by summing the scores on the items and dividing them by the total number of items.

Univariate linear regression analysis was performed for each of the independent variables (scale for an open culture in the work environment, six support items) and the dependent variable (scale for changes in professional practice). We considered differences to be significant when the $\mathrm{p}$ value was $<0.05$.

Questions that were answered as 'not applicable' were coded as missing. Missing values were left out.

Patient and public involvement

No patient were involved.

\section{RESULTS}

General characteristics of the study population and complaint process

Men $(78.7 \%)$ and the over-50 age groups (together $75.2 \%$, table 1) are over-represented in our study population. In contrast, in the total Dutch population of doctors in $2015,49.4 \%$ were men, and $6.2 \%$ (data are only available for those aged 65 years and older) were older than 65 years. $^{37}$ In our study population, $38.4 \%$ were GPs, $48.2 \%$ medical specialists and $13.4 \%$ other (for instance, a medical doctor in training). For more than one-third of the respondents, more than 2 years had gone by since 
Table 1 Characteristics of the study population $(n=207-210)$

\begin{tabular}{ll}
\hline & Total (\%) \\
\hline Age (years) & \\
$\leq 39$ & 5.2 \\
$40-49$ & 19.5 \\
$50-59$ & 38.1 \\
$\geq 60$ & 37.1 \\
Male & 78.7 \\
Female & 21.3 \\
\hline
\end{tabular}

they received their warning or reprimand (not in table). Of all the respondents, $78.6 \%$ were given a warning and $21.4 \%$ a reprimand.

\section{Open culture}

Most doctors experience their work environment as open in the sense that they feel it is safe to talk about adverse events and report adverse events (71.2\%); just 9.1\% disagree (table 2).

Extra analyses were carried out to see whether younger doctors responded differently from older doctors for the variables concerning open culture, but no significant differences were found. Men were more positive about having a safe environment in which to talk about and report adverse medical events than women.

\section{Experienced support during the disciplinary procedure}

Doctors were most likely to have felt supported by a lawyer or legal representative, their colleagues and their supervisor (table 3). Few doctors felt obstructed during the disciplinary procedure.

\section{Perceived changes to professional practice due to the disciplinary procedure}

Doctors reported an influence of the procedure on professional practice (table 4). For many doctors, the influence of the disciplinary procedure has been mostly negative $(47.4 \%)$, but one-third of doctors reported both a negative and a positive influence $(33.5 \%)$.

Table 5 shows what kind of changes doctors reported as due to the disciplinary procedure. The changes reported most were discussing improvement measures with colleagues and/or managers $(60.8 \%)$, trying to avoid risky patients $(43.1 \%)$ and doing supplementary tests earlier $(41.3 \%)$.

We found no significant relationship between an open culture and perceived changes to professional practice (table 6). Neither was there a significant relationship between the level of support from colleagues or supervisors and perceived changes to professional practice. Feeling supported by a lawyer and/or legal representative, however, is associated with less change in professional practice. Also feeling supported by a professional confidant or professional association is associated with less change in professional practice.

\section{DISCUSSION}

Given that the procedure aims to correct professionals' behaviour, it is to be expected that doctors experiencing a disciplinary procedure perceive changes to their professional practice as a result.

Despite the finding that a majority of doctors state they have discussed changes with colleagues or managers, the impact of the disciplinary procedure is mostly seen as negative. Our findings are further put into perspective by the relatively low percentage of doctors $(26.3 \%)$ who also believed that implementing improvement measures was necessary. Furthermore, in line with the results by Bruers $e t a l^{4}$, we found that one-third of the respondents perceive the impact of the disciplinary procedure as negative and positive simultaneously. ${ }^{2}$ As we concluded in our earlier study, learning, if it occurs at all, comes at a high price.

We found that assigning the label 'defensive medicine' to the reported changes is not always obvious or appropriate. In part, this is because defensive medicine as a concept can be 'slippery ${ }^{38}$ as it is defined by subjective factors such as the intent of the professional ${ }^{39}$ and as it harbours a negative connotation that might not always be appropriate because the result is not always harmful or because it is even intended.

Defensive medicine can take the form of either assurance (positive) behaviour or avoidance (negative) behaviour. Whereas avoidance behaviour is obviously undesirable, for assurance behaviour the result might not necessarily be detrimental to the quality of care. Summerton's distinction between positive and negative factors in defensive medicine might be helpful in interpreting our results as either undesired or positive changes. ${ }^{14}$

Table 2 Indicate your agreement with the following statements $(n=206-210)$

\begin{tabular}{llll}
\hline & $\begin{array}{l}\text { Agree/totally } \\
\text { agree (\%) }\end{array}$ & Neutral (\%) & $\begin{array}{l}\text { Disagree/totally } \\
\text { disagree (\%) }\end{array}$ \\
\hline $\begin{array}{l}\text { In my work environment, it was safe to address unsafe behaviour } \\
\text { In my work environment, there were good preconditions for }\end{array}$ & 63.6 & 27.2 & 9.2 \\
$\begin{array}{l}\text { reporting adverse events } \\
\begin{array}{l}\text { In my work environment, there was a safe culture to talk about } \\
\text { and report adverse events }\end{array}\end{array}$ & 71.4 & 19.4 & 9.2 \\
\hline
\end{tabular}


Table 3 Have you experienced support or obstruction during the disciplinary procedure? $(n=26-195)^{*}$

\begin{tabular}{|c|c|c|c|}
\hline & $\begin{array}{l}\text { A little/a lot of } \\
\text { obstruction (\%) }\end{array}$ & $\begin{array}{l}\text { No support and no } \\
\text { obstruction (\%) }\end{array}$ & $\begin{array}{l}\text { A little/a lot of } \\
\text { support (\%) }\end{array}$ \\
\hline One or more colleagues $(n=195)$ & 2.1 & 8.7 & 89.2 \\
\hline A lawyer or other legal representative $(n=181)$ & 3.9 & 3.3 & 92.8 \\
\hline A complaints officer $(n=65)$ & 4.6 & 50.8 & 44.6 \\
\hline
\end{tabular}

*For each category of support, respondents could answer N/A. Respondents answering N/A were excluded from the analysis.

Summerton distinguishes between learning and performing on a suboptimal clinical and social level. Discussing improvement measures $(60.8 \%)$, seeing that it was necessary to implement improvement measures $(26.3 \%)$, trying to communicate better with patients $(26.7 \%)$ and signalling dissatisfaction more quickly $(16.0 \%)$ could be considered examples corresponding with Summerton's examples of positive changes. In the light of quality improvement, this could be promising as this is the result the disciplinary procedure seeks to achieve.

Summerton lists both avoidance and assurance behaviours as examples of negative factors in defensive medicine. The corresponding behaviour reported by doctors in our study could be avoidance behaviour such as trying to avoid risky patients (43.1\%), avoiding patients similar to the complainant $(32.0 \%)$ and avoiding certain actions $(27.6 \%)$. Doing more supplementary tests $(41.3 \%)$ would be a negative factor associated with assurance behaviour, as could giving in to the wishes of patients (if we can assume the patient desires more medication, treatment or research) (35\%).

We assumed that working in an open culture would make it easier for doctors to reach out for support and that both working in an open culture and feeling supported would result in the disciplinary procedure having less of a negative impact. At the same time, disciplinary procedures are potentially stigmatising ${ }^{3}$ and disciplinary complaints are confidential. This means that most doctors needing support will actively need to reach out themselves. A promising result of our study, therefore, is that doctors in our study generally perceive their work

Table 4 How has the disciplinary procedure influenced your professional practice? $(n=209)$

\begin{tabular}{lc}
\hline & $\%$ \\
\hline $\begin{array}{l}\text { The procedure had a mostly negative influence } \\
\text { The procedure had both a negative and a positive }\end{array}$ & 47.4 \\
influence & 33.5 \\
The procedure had a mostly positive influence & 7.7 \\
\hline The procedure had no influence & 11.5 \\
\hline
\end{tabular}

environment as open and indicate that they feel safe to address unsafe behaviour and adverse medical events.

Whereas Bourne et at $t^{40}$ report bullying and undermining during complaint procedures, only a few doctors in our study felt obstructed ('tegengewerkt' in the original Dutch questionnaire, which can also mean 'undermined'), and a number of doctors in our study sought and found support within their work environment. Doctors mostly felt supported by colleagues and supervisors. Still, feeling supported by colleagues was not associated with perceived changes in professional practice and neither was the support from supervisors. The necessity of an open culture and support within the work environment notwithstanding, working in an open and supportive environment does not seem to be sufficient to offset the negative perception doctors have of the impact of disciplinary procedures.

We can offer several explanations that are feasible, but further inquiry would be needed to provide clear answers as to why this relationship was not found. Adequately supporting doctors as 'second victims' has only recently taken shape in the Netherlands, mostly within hospitals and almost exclusively within the context of patient safety

Table 5 Percentage of doctors who agree or totally agree with statements about changes in their professional practice due to the disciplinary procedure $(n=166-184)$

\section{Since the disciplinary process:}

Total (\%)

I have discussed possible improvement measures 60.8 with my colleagues/managers

I try to avoid risky patients

43.1

I do supplementary tests earlier

41.3

I see each patient as a potential new complainant 37.4

I give in to the wishes of patients earlier 35.0

I avoid patients similar to the complainant

32.0

I avoid certain actions $\quad 27.6$

I see that it was necessary to implement 26.3 improvement measures

I try to communicate better with patients $\quad 26.7$

I am able to spot dissatisfaction in patients earlier 16 
Table 6 Univariate linear regression analyses of the effect of open culture and support on changes to professional practice (outcome variable)

\begin{tabular}{lccc}
\hline & $\begin{array}{l}\text { Unstandardised } \\
\text { Coefficient B }\end{array}$ & T value & P value \\
\hline $\begin{array}{l}\text { Open culture } \\
\text { Support of colleagues }\end{array}$ & -0.112 & -1.69 & 0.092 \\
\hline $\begin{array}{l}\text { Support of supervisors } \\
\text { Support of lawyer }\end{array}$ & -0.06 & 0.98 & 0.328 \\
$\begin{array}{l}\text { Support of complaints } \\
\text { officer }\end{array}$ & -0.107 & -0.84 & 0.401 \\
$\begin{array}{l}\text { Support of } \\
\text { professional confidant }\end{array}$ & -0.231 & -1.98 & 0.049 \\
$\begin{array}{l}\text { Support of } \\
\text { professional } \\
\text { association }\end{array}$ & -0.529 & -2.22 & 0.202 \\
\hline
\end{tabular}

${ }^{*} \mathrm{P}<0.05$

incidents. ${ }^{41}$ This means that for many doctors in our study, for whom the procedure took place before 2016, it might have been difficult to identify adequate support. Another explanation might be that the procedure is damaging to such an extent that supporting the doctor is simply not sufficient to prevent negative consequences for practice. We hope the recent legislative change concerning the disclosure of disciplinary measures helps to relieve this impact. Still, for a substantial proportion of our respondents with a warning $(78.6 \%)$, the measure was not disclosed.

Besides colleagues and supervisors, doctors also felt supported by a lawyer and/or other legal representatives. Legal representatives are sometimes employed by healthcare institutions, or they can be provided by doctors' liability insurers or hired by the doctors themselves. We found a significant relationship between the support of a lawyer or a professional confidant and perceived changes to professional practice. Doctors who reported more legal support also reported fewer changes to their professional practice. The strongest effect we found was from support by a professional association. As we had no knowledge of organised support by professional organisations, we made enquiries with the Royal Dutch Medical Association (KNMG) as to what this support might entail. KNMG provides support through the 'Doctors' info line' ('Artseninfolijn'). Doctors can contact the info line with questions on legal and ethical issues, but the info line offers a sympathetic ear as well. Given our results, this is a feature that deserves greater attention.

Our results seem to suggest that to prevent defensive practice, doctors receiving a disciplinary complaint might do well to seek legal advice. Equally, employers and/ or supervisors informed about disciplinary proceedings would do well to provide legal representation or urge doctors to seek legal advice. However, involving legal professionals can lead to a more formal and adversarial course of proceedings. As adversarial legal proceedings can be harmful in their own right, ${ }^{2}{ }^{42-45}$ further research into the form and content of helpful, restorative legal representation is necessary to provide the legal support healthcare professionals need.

Another implication for further research might be the gender difference we found as regards having a safe environment in which to report and talk about patient safety incidents. Our findings are in line with those from Martowirono $e t a t^{46}$ speculate that women might be more safety-oriented than men and more likely to communicate about patient safety. Another explanation might be offered by the various studies demonstrating the continuing prevalence of gender inequality in healthcare. ${ }^{47} 48$ A recent study analysing performance evaluations of first-year and third-year residents in emergency medicine has shown that women making medical errors receive harsher comments in comparison with their male counterparts. Also, making errors is seen as limiting their ability to practise emergency medicine, whereas men making similar mistakes are still seen as able to pursue a career in academic medicine. ${ }^{49}$ Taking these results into account, the perceived safety of the work environment might also be influenced by the fact that 'it's a man's world'.

\section{CONCLUSION}

At first glance, our results seem to indicate that disciplinary procedures have both positive and negative effects on professional practice. Discussing improvement measures and trying to communicate better with patients, for instance, can be defined as a positive change or as learning from the procedure. This is what the disciplinary procedure seeks to achieve.

Most doctors, however, perceived the disciplinary procedure as having a negative effect, raising the question of whether the potential to learn from the procedure is realised in practice. Furthermore, disciplinary procedures trigger negative practices, such as avoiding risky patients, which can be seen as an undesired response to the particular characteristics of the disciplinary complaint.

The literature concerning 'second victims' bears out the reasoning that supporting doctors after adverse medical events helps to reduce the negative impact of adverse medical events on healthcare professionals. Our results show that supporting doctors in the work environment is not a panacea. Combining these insights with our preceding conclusions concerning the impact on health, personal and professional functioning and career opportunities, the gains of disciplinary procedures do not seem to outweigh the costs, raising serious questions regarding the management of disciplinary complaints.

\section{Limitations}

This study provides insight into the impact of disciplinary procedures on doctors' professional practice and whether or not these changes are associated with an open culture 
and support. We interpreted our results within the context of defensive medicine. As defensive medicine can be a slippery concept, we have added valuable reflection to the body of research concerning the consequences of defensive practice and whether or not changes in practices are positive or negative. As disciplinary procedures are aimed at quality improvement, this is a valuable addition to the existing body of research. Disciplinary procedures are found in differing jurisdictions. While taking the differing specifics into account, our findings can be informative for those countries with similar legal structures.

Following our research concerning the impact of disclosing disciplinary measures, Dutch legislation was amended in 2019. Disciplinary boards now have the discretionary competence to only disclose the disciplinary measure when deemed appropriate or necessary. Respondents in our study received measures that were published online and in newspapers, which influences the severity of the perceived impact.

The response rate might be seen as moderate, and there may be a non-response bias. However, disciplinary procedures are a potentially traumatic and stigmatic experience. Given the sensitivity of the topic, meticulous privacy arrangements were made. Therefore, no data on characteristics are available for the non-respondents, and a non-response analysis was not possible. An important reason for the non-response could be that filling in the questionnaire made respondents uncomfortable because it revived memories of the situation that the complaint was about. Another reason could be that the disciplinary procedure was already a great burden, making people reluctant to participate. Given these circumstances, the resulting response rate was good.

One consequence of the moderate response rate could be that the study population is not representative of the entire group of doctors who received a disciplinary measure. Possibly, a specific group of disciplined doctors, for instance, those who feel more empowered, may have responded to our questionnaire. The opposite might also be true: those doctors who feel less empowered may have responded to our questionnaire, for instance, doctors who are not able to put the disciplinary experience behind them.

The study population was not comparable with the Dutch population of doctors in terms of age and gender. It is unclear why the percentage of men is so high in the study population. One potential explanation might be that male doctors attract more disciplinary complaints, as was found by Cunningham et al. ${ }^{50}$ The fact that the study population is older compared with the Dutch population can be explained by the fact that the older the doctor, the more chance there is that they will at some point have had a complaint filed against them. It might also be that the percentage of male doctors is higher in that particular, older population.

The study design is retrospective and the perceived impact is self-reported. Given our research question, this was the best feasible design, giving a valuable insight into the experiences of doctors who have been disciplined. However, a causal relationship between a perceived open culture and support and the perceived impact of the disciplinary procedure cannot be proven with this design, and the severity of the disciplinary measure might influence the perceived impact.

\section{Author affiliations}

${ }^{1}$ Faculty of Law, Vrije Universiteit Amsterdam, Amsterdam, The Netherlands ${ }^{2}$ Nivel, Utrecht, The Netherlands

${ }^{3}$ Nivel; TRANZO (Scientific Centre for Care and Welfare), Faculty of Social and Behavioural Sciences, Tilburg University, Tilburg, The Netherlands

Acknowledgements The authors sincerely thank the people who filled in a questionnaire for their co-operation.

Contributors BSL, RJRB, AJEdV and RDF participated in the design of the principal study. RJRB analysed the data. BSL, RJRB, AJEdV and RDF interpreted the analyses. BSL and RJRB drafted the manuscript. All authors critically revised and approved the final manuscript. All authors agreed to be personally accountable for the author's own contributions and for ensuring that questions related to the accuracy or integrity of any part of the work, even ones in which the author was not personally involved, are appropriately investigated, resolved and documented in the literature.

Funding This study was funded by the Dutch Ministry of Health, Welfare and Sports.

Competing interests None declared.

Patient consent for publication Not required.

Ethics approval This study was based on questionnaires completed by doctors; no patients were involved. As all the research participants were competent individuals and no participants were subjected to any interventions or actions, no ethical approval was needed under Dutch law on medical research (Medical Research Involving Human Subjects Act, www.ccmo.nl). Participation in the study was voluntary. The questionnaire data were stored and analysed anonymously, in accordance with the Dutch Personal Data Protection Act (www.privacy.nl/uploads/ guide_for_controller_ministry_justice.pdf).

Provenance and peer review Not commissioned; externally peer reviewed.

Data availability statement Data are available upon reasonable request. Extra data are available by emailing Berber Laarman, b.s.laarman@vu.nl.

Open access This is an open access article distributed in accordance with the Creative Commons Attribution Non Commercial (CC BY-NC 4.0) license, which permits others to distribute, remix, adapt, build upon this work non-commercially, and license their derivative works on different terms, provided the original work is properly cited, appropriate credit is given, any changes made indicated, and the use is non-commercial. See: $\mathrm{http}: / /$ creativecommons.org/licenses/by-nc/4.0/.

ORCID iD

Berber S Laarman http://orcid.org/0000-0002-4029-7748

\section{REFERENCES}

1 Laarman BS, Bouwman RJ, de Veer AJ, et al. How do doctors in the Netherlands perceive the impact of disciplinary procedures and disclosure of disciplinary measures on their professional practice, health and career opportunities? A questionnaire among medical doctors who received a disciplinary measure. BMJ Open 2019;9:e023576.

2 Bourne T, Wynants L, Peters M, et al. The impact of complaints procedures on the welfare, health and clinical practise of 7926 doctors in the UK: a cross-sectional survey. BMJ Open 2015;5:e006687.

3 Verhoef LM, Weenink J-W, Winters S, et al. The disciplined healthcare professional: a qualitative interview study on the impact of the disciplinary process and imposed measures in the Netherlands. BMJ Open 2015;5:e009275.

4 Bruers JJM, van Dam BAFM, Gorter RC, et al. The impact of a formal complaint on Dutch dentists' professional practice: a survey study. BMC Oral Health 2016;16:104. 
5 Wu AW. Medical error: the second victim. The doctor who makes the mistake needs help too. BMJ 2000;320:726.

6 Van Gerven E. Health professionals as second victims of patient safety incidents: impact on functioning and well-being (PHD diss). Leuven: KU Leuven, 2016.

7 Coughlan B, Powell D, Higgins MF. The second victim: a review. Eur J Obstet Gynecol Reprod Biol 2017;213:11-16.

8 Vanhaecht K, Seys D, Schouten L, et al. Duration of second victim symptoms in the aftermath of a patient safety incident and association with the level of patient harm: a cross-sectional study in the Netherlands. BMJ Open 2019;9:e029923.

9 Studdert DM, Mello MM, Sage WM, et al. Defensive medicine among high-risk specialist physicians in a volatile malpractice environment. JAMA 2005;293:2609-17.

10 Garattini L, Padula A. Defensive medicine in Europe: a 'full circle'? Berlin, Germany: Springer, 2020.

11 Baungaard N, Skovvang P, Assing Hvidt E, et al. How defensive medicine is defined and understood in European medical literature: protocol for a systematic review. BMJ Open 2020;10:e034300.

12 Assing Hvidt E, Lykkegaard J, Pedersen LB, et al. How is defensive medicine understood and experienced in a primary care setting? A qualitative focus group study among Danish general practitioners. BMJ Open 2017;7:e019851.

13 Anderson RE. Billions for defense: the pervasive nature of defensive medicine. Arch Intern Med 1999;159:2399-402.

14 Summerton N. Positive and negative factors in defensive medicine: a questionnaire study of general practitioners. BMJ 1995;310:27-9.

15 Boothman R, Hoyler MM. The University of Michigan's early disclosure and offer program. Bull Am Coll Surg 2013;98:21.

16 ledema RAM, Mallock NA, Sorensen RJ, et al. The National open disclosure pilot: evaluation of a policy implementation initiative. Med J Aust 2008;188:397-400.

17 O'Connor E, Coates HM, Yardley IE, et al. Disclosure of patient safety incidents: a comprehensive review. Int J Qual Health Care 2010;22:371-9.

18 Wu AW, Boyle DJ, Wallace G, et al. Disclosure of adverse events in the United States and Canada: an update, and a proposed framework for improvement. J Public Health Res 2013;2:e32.

19 Lipira LE, Gallagher TH. Disclosure of adverse events and errors in surgical care: challenges and strategies for improvement. World $\mathrm{J}$ Surg 2014;38:1614-21.

20 Pinto A, Faiz O, Bicknell C, et al. Surgical complications and their implications for surgeons' well-being. Br J Surg 2013;100:1748-55.

21 Vincent C, Young M, Phillips A. Why do people sue doctors? A study of patients and relatives taking legal action. Lancet 1994;343:1609-13.

22 Relis T. It's not about the money: a theory of misconceptions of plaintiffs' litigation aims. U Pitt L Rev 2006;68:701.

23 Dekker S. Just culture: restoring trust and accountability in your organization. CRC: Burlingon, 2017.

24 Dekker SWA, Hugh TB. Balancing 'no blame' with accountability in patient safety. N Engl J Med 2010;362:275.

25 Wachter RM, Pronovost PJ. Balancing 'no blame' with accountability in patient safety. N Engl J Med 2009;361:1401-6.

26 Dekker M. Het medisch tuchtrecht wordt strafrecht light, in NRC Handelsblad, the Netherlands [Accessed 28 May 2015].

27 Giard R. Medisch tuchtrecht: duidelijke bestaansredenen, onzeker nut. Ned Tijdschr Geneeskd 2006;150:2830.

28 Hendriks AC. Tuchtrecht-meer tucht DAN recht TvGR 2015:322-30.

29 Scott SD, Hirschinger LE, Cox KR, et al. Caring for our own: deploying a systemwide second victim rapid response team. Jt Comm J Qual Patient Saf 2010;36:233-40.

30 Wu AW, Steckelberg RC. Medical error, incident investigation and the second victim: doing better but feeling worse? BMJ Qual Saf 2012;21:267-70.

31 Plews-Ogan M, May N, Owens J, et al. Wisdom in medicine: what helps physicians after a medical error? Acad Med 2016;91:233-41.

32 Tedeschi RG, Calhoun LG. The posttraumatic growth inventory: measuring the positive legacy of trauma. $J$ Trauma Stress 1996;9:455-71.
33 Hooftman WE MG, Janssen B, de Vroome EMM, et al. Methodologie en globale resultaten. 2016, TNO/CBS. Heerlen: Leiden, 2015.

34 Alhafaji $Y$, Frederiks B, Legemaate J. Ervaringen van klagers en aangeklaagde artsen met het tuchtrecht [Experiences of complainants and accused doctors with the disciplinary System]. Nederlands-Vlaams tijdschrift voor Mediation en conflictmanagement 2009;13:18-42.

35 Heuver G, Heijboer L, Schilp J, et al. "Just culture": inzicht in calamiteitenbeleid in Nederlandse zorginstellingen. Een onderzoek naar hoe ziekenhuis omgaan met (potentiële) calamiteiten. KIZ: Tijdschrift over Kwaliteit en Veiligheid in Zorg 2015;3:24-7.

36 Drennan J. Cognitive interviewing: verbal data in the design and pretesting of questionnaires. J Adv Nurs 2003;42:57-63.

37 CBS. CBS Statline 2015.

38 Studdert DM, Mello MM, Brennan TA. Defensive medicine and tort reform: a wide view. Berlin, Germany: Springer, 2010.

39 Hermer LD, Brody H. Defensive medicine, cost containment, and reform. J Gen Intern Med 2010;25:470-3.

40 Bourne T, De Cock B, Wynants L, et al. Doctors' perception of support and the processes involved in complaints investigations and how these relate to welfare and defensive practice: a cross-sectional survey of the UK physicians. BMJ Open 2017;7:e017856.

41 Laarman BS, Akkermans AJ, Legemaate J, et al. Ervaringen met de organisatie van een OPEN beleid in Nederlandse ziekenhuizen: verslag en resultaten van handelingsonderzoek. Amsterdam/ Utrecht: Vrije Universiteit Amsterdam, Nivel, Amsterdam UMC, Fonds Slachtofferhulp 2018.

42 Laarman BS. Just culture en herstelrecht in de afwikkeling van medische schade. Tijdschrift voor Vergoeding Personenschade 2019;22:65-83.

43 Charles SC, Pyskoty CE, Nelson A. Physicians on trial-self-reported reactions to malpractice trials. West J Med 1988;148:358.

44 Balch CM, Oreskovich MR, Dyrbye LN, et al. Personal consequences of malpractice lawsuits on American surgeons. J Am Coll Surg 2011;213:657-67.

45 Bourne T, Vanderhaegen J, Vranken R, et al. Doctors' experiences and their perception of the most stressful aspects of complaints processes in the UK: an analysis of qualitative survey data. BMJ Open 2016;6:e011711.

46 Martowirono K, Wagner C, Bijnen AB. Surgical residents and patient safety climate. J Eval Clin Pract 2014;20:121-8.

47 Backhus LM, Fann BE, Hui DS, et al. Culture of safety and gender inclusion in cardiothoracic surgery. Ann Thorac Surg 2018;106:951-8.

48 Kang SK, Kaplan S. Working toward gender diversity and inclusion in medicine: myths and solutions. Lancet 2019;393:579-86.

49 Brewer Aet al. Who gets the benefit of the doubt? performance evaluations, medical errors, and the production of gender inequality in emergency medical education. American Sociological Review 2020;85): :247-70.

50 Cunningham W, Crump R, Tomlin A. The characteristics of doctors receiving medical complaints: a cross-sectional survey of doctors in New Zealand. N Z Med J 2003;116:U625.

51 Hout E, Friele R, Legemaate J. De burger ALS klager in Het tuchtrecht voor de gezondheidszorg. Weinig klachten, mogelijk door geringe kennis van tuchtrechtsysteem. Ned Tijdschr Geneeskd 2009;153: :A548.

52 Laarman B, Akkermans AJ. Compensation schemes for damage caused by healthcare and alternatives to court proceedings in the Netherlands. 2018, the Netherlands national report to the 20th general congress of the international academy of comparative law Fukuoka, Japan, 2018.

53 Vries de, Sanderson P, Janta B, et al. International comparison of ten medical regulatory systems: Egypt, Germany, Greece, India, Italy, Nigeria, Pakistan, Poland, South Africa and Spain. Santa Monica, CA: RAND Corporation, 2009. https://www.rand.org/pubs/technical_ reports/TR691.html.

54 Borow M, Levi B, Glekin M. Regulatory tasks of national medical associations - international comparison and the Israeli case. Isr J Health Policy Res 2013;2:8. 